\title{
Patients' Satisfaction with Services Obtained from a Health Care Centre in Rural Bangladesh
}

\author{
Farzana Mahejabin ${ }^{1}$, Rezaul Farid Khan ${ }^{2}$, Shamima Parveen ${ }^{3}$
}

\begin{abstract}
Background: Patients' satisfaction is one of the established yard sticks to measure success of the services being provided in the hospitals. Human satisfaction is a complex concept. A satisfied patient is more likely to develop a deeper and longer lasting relationship with their medical providers, leading to improved compliance, continuity of care, and ultimately better outcomes. Objective: To assess patient satisfaction with services provided in a primary health care centre in rural Bangladesh. Materials and method: This descriptive cross sectional study was carried out among the patients who attended the outpatient department at Upazilla Health Complex, Dhamrai from November 2015 to January 2016. Study subjects were selected by convenient type of non-probability sampling. Semi-structured pre-tested questionnaire was used and face to face interview was conducted. A Total of 328 respondents, age more than 18 years, irrespective of sex, were included in this study. Results: Majority of the patients stated that the general basic facilities, in terms of lighting facilities, signboards, canteen services and toilet facilities at the hospital were adequate. Majority respondents reported that the hospital was clean, ventilation facilities were found adequate, sitting arrangements and drinking water was available in waiting rooms. Most of the patients were satisfied with the behaviour of health personnel and quality of professional services provided by doctors. Regarding overall satisfaction, $44.2 \%$ patients were satisfied with health services and only 3.0\% patients were dissatisfied. A high statistically significant relation was found between educational level and occupation with satisfaction level of the respondents. Conclusion: The health care delivered at this centre can be improved further by monitoring the delivery ofquality care by ongoing basis and continually making small changes as per need so as to improve the individual processes.
\end{abstract}

Keywords: Patient satisfaction; primary health care centre; quality care.

Delta Med Col J. Jul 2016;4(2):77 - 82

\section{Introduction}

Patients' satisfaction is considered as one of the desired outcome of healthcare, and it is directly related to utilization of health services.
Measurement of patient satisfaction involves multi-dimensional aspects of patients' opinion on healthcare, identifying problems in healthcare, and

1. Associate Professor \& Head, Department of Community Medicine, Dhaka Community Medical College, Dhaka, Bangladesh.

2. Associate Professor, Department of Community Medicine, Delta Medical College, Dhaka, Bangladesh.

3. Lecturer, Department of Community Medicine, Dhaka Community Medical College, Dhaka, Bangladesh.

Correspondence: Dr. Farzana Mahejabin. e-mail: farzanamahejabin@yahoo.com 
evaluation of healthcare. ${ }^{1}$ Health care scenario is fast changing all over the world. ${ }^{2}$ Patient satisfaction is one of the established yard sticks to measure success of the services being provided in the hospitals. ${ }^{3}$ Improved socioeconomic status and easier access to medical care has led to high expectations and demands from consumers of hospital services. ${ }^{4}$ For health care organization to be successful monitoring of customer's perception is a simple but important strategy to assess and improve their performance. ${ }^{5,6} \mathrm{~A}$ patient is the ultimate consumer of the hospital. He is the person in distress. He expects from hospital comfort, care and cure. ${ }^{3}$ Patient forms certain expectations prior to visit. Once the patients come to the hospital and experience the facilities, they may become either satisfied or dissatisfied. ${ }^{2}$

Human satisfaction is a complex concept that is related to a number of factors including lifestyle, past experiences, future expectations and the value of both individual and society. ${ }^{7}$ Patients' satisfaction is a component of health care quality and is increasingly being used to assess medical care in many countries in the world. Until recently, traditional assessments of medical care were done purely in terms of technical and psychological reports of outcomes. It is an established fact that satisfaction influences whether a person seeks medical advice, complies with treatment and maintains a continuing relationship with practitioners. ${ }^{8}$ Patient satisfaction has long being considered an important component when measuring health outcomes and quality of care. The rising strength of consumerism in society highlights the central role of patient's attitude play in health planning and delivery. Furthermore, a satisfied patient is more likely to develop a deeper and longer lasting relationship with their medical providers, leading to improved compliance, continuity of care, and ultimately better outcomes. $^{9}$

Keeping this background in mind the present study was undertaken to assess the quality of care provided in outpatient department of a primary health care centre in rural Bangladesh regarding patients' satisfaction.

\section{Materials and method}

This descriptive cross-sectional analytical study was conducted to assess the patient's satisfaction with services provided in a primary health care centre in rural Bangladesh for a period of three months starting from November 2015 to January 2016. The study was carried out among the patients attending the outpatient department (OPD)ofUpazillaHealth Complex, Dhamrai, Bangladesh. Initially a total of 380 patients were enrolled for the study. The study subjects were selected by convenient type of non-probability sampling. A patient attending the OPD and having age above 18 years of both male and female was included in the study. Patients who were very busy with other assignments and who regretted to spend time were excluded in enrolment process. Patient working in the health care centre and patients with severe physical or mental pathologies, such as terminal disease and psychosis, were excluded from the study. Finally 328 subjects participated in this study. Informed verbal consent was taken from each patient and they were ensured about the confidentiality. A semi-structured pre-tested questionnaire was used which included socio-demographic profile and certain domains of satisfaction such as basic facilities, satisfaction towards OPD services regarding courtesy and quality of care. Face to face interview was taken to collect data. The patients were requested to give rating to these statements. Likert's 5 points rating scale was used. ${ }^{10}$ The rating was done as following: 1 -strongly satisfied, 2 - satisfied, 3 neither satisfied nor dissatisfied, 4 - Dissatisfied, 5 - strongly dissatisfied. The level of satisfaction was classified into three groups: 1-Satisfied, 2-Neither satisfied nor dissatisfied, and 3-Dissatisfied. Total score of courtesy and quality of care were calculated for each aspects of satisfaction. Data entry and analyses were done by using SPSS, version 22 for Widows. The mean, 
standard deviation, and frequency distribution were calculated. Chi-Square and ANOVA were done to analyze the data.

\section{Results}

A total of 328 patients attending in OPD were included in the study. Most (54\%) of the respondents were female and $33.5 \%$ respondentswere within 21-30 years of age. Mean age was $33.30 \pm 13.61$ years. Majority of the respondents (42.1\%) were house wife, educated up to primary level (36\%), and per capita income was between TK. 2001-4000 (37.5\%) (Table I).

Table I: Distribution of the respondents by socio-demographic characteristics $(\mathrm{N}=328)$

\begin{tabular}{llcc}
\hline Variables & & Frequency & Percentage \\
\hline Gender & Male & 151 & 46.0 \\
& Female & 177 & 54.0 \\
Age (year) & $\leq 20$ & 62 & 18.9 \\
& $21-30$ & 110 & 33.5 \\
& $31-40$ & 92 & 28.0 \\
& $41-50$ & 24 & 7.3 \\
& $51-60$ & 28 & 8.5 \\
& $>60$ & 12 & 3.7 \\
Education & Illiterate / no schooling & 70 & 21.3 \\
& Primary & 118 & 36.0 \\
& Secondary & 93 & 28.4 \\
& Higher secondary and above & 47 & 14.3 \\
Occupation & Housewife & 138 & 42.1 \\
& Agriculture worker & 41 & 12.5 \\
& Day labourer & 38 & 11.6 \\
Per capita income & $\leq 2,000$ & 42 & 12.8 \\
& Service holder & 69 & 21.0 \\
& Ot,001 - 4,000 & 65 & 20.4 \\
Family income & $<10,000$ & 196 & 59.8 \\
(BDT) / year & 10,000 - 20,000 & 65 & 19.8 \\
& $>$ 20,000 & 119 & 36.3 \\
& & 123 & 37.5 \\
& & 26.2 \\
\hline
\end{tabular}

Majority of the patients stated that the general basic facilities at the hospital were adequate. Most $(87.2 \%)$ of the respondents were satisfied with lighting arrangement, signboards locating department $(86.6 \%)$, availability of food $(75.3 \%)$ and toilet facilities (72.9\%). More than 50\% respondents reported that the hospital was clean $(68.6 \%)$, fans were adequate $(67.4 \%)$, seats were available in waiting room (55.5\%) and drinking water was adequate (55.2\%) (Table II).

Table II: General basic facilities in the hospital $(\mathrm{N}=328)$

\begin{tabular}{lcc}
\hline Basic facilities in the hospital & $\begin{array}{c}\text { Adequate } \\
\text { Frequency (\%) }\end{array}$ & $\begin{array}{c}\text { Inadequate } \\
\text { Frequency (\%) }\end{array}$ \\
\hline Toilets & $239(72.9)$ & $89(27.1)$ \\
Drinking water & $181(55.2)$ & $147(44.8)$ \\
Cleanliness & $225(68.6)$ & $103(31.4)$ \\
Canteen / food facilities & $247(75.3)$ & $81(24.7)$ \\
Lighting arrangement & $286(87.2)$ & $42(12.8)$ \\
Waiting room/ availability of sitting facilities & $182(55.5)$ & $146(44.5)$ \\
Ventilation & $221(67.4)$ & $107(32.6)$ \\
Signboards locating departments & $284(86.6)$ & $44(13.4)$ \\
\hline
\end{tabular}

Most $(96.6 \%)$ of the patients were satisfied with the behaviour of doctors, nurses $(84.4 \%)$, pharmacists $(72 \%)$, registration clerk $(79.6 \%)$ and of supporting staff (83.5\%). Very few respondents were dissatisfied with doctors, nurses, pharmacists, registration staff and other staff's behaviour (Table III).

Table III: Distribution of the respondent's satisfaction towards OPD services regarding courtesy $(\mathrm{N}=328)$

\begin{tabular}{lccccc}
\hline Parameter & \multicolumn{5}{c}{ Level of satisfaction } \\
& $\begin{array}{l}\text { Strongly } \\
\text { satisfied } \\
(\%)\end{array}$ & $\begin{array}{c}\text { Satisfied } \\
(\%)\end{array}$ & $\begin{array}{c}\text { Neither satisfied } \\
\text { nor dissatisfied } \\
(\%)\end{array}$ & $\begin{array}{c}\text { Dissatisfied } \\
(\%)\end{array}$ & $\begin{array}{c}\text { Strongly } \\
\text { dissatisfied } \\
(\%)\end{array}$ \\
\hline $\begin{array}{l}\text { Behaviour of } \\
\text { the doctor }\end{array}$ & $65(19.8)$ & $252(76.8)$ & $8(2.4)$ & $3(0.9)$ & $0(0.0)$ \\
$\begin{array}{l}\text { Behaviour of } \\
\text { the nurse }\end{array}$ & $30(9.1)$ & $247(75.3)$ & $39(11.9)$ & $9(2.7)$ & $3(0.9)$ \\
$\begin{array}{l}\text { Behaviour of } \\
\text { the pharmacist }\end{array}$ & $32(9.8)$ & $204(62.2)$ & $72(22.0)$ & $15(4.6)$ & $5(1.5)$ \\
$\begin{array}{l}\text { Behaviour of } \\
\text { the registration clerk }\end{array}$ & $14(4.3)$ & $247(75.3)$ & $45(13.7)$ & $22(6.7)$ & $0(0.0)$ \\
$\begin{array}{l}\text { Behaviour of } \\
\text { supporting staff }\end{array}$ & $10(3.0)$ & $264(80.5)$ & $34(10.4)$ & $19(5.8)$ & $1(0.3)$ \\
\hline
\end{tabular}

Most (96.3\%) of the respondents were quite satisfied with the quality of professional services by doctor. Majority (76.2\%) of the respondents stated that doctors were cooperative about explaining the reason for medical test and (78.6\%) 
respondents noted that nurses were skilled in using medical equipments and were very cooperative to the patient. About $81 \%$ patients were also satisfied with pharmacists regarding explanation of medicines written in prescriptions and $76.2 \%$ were satisfied with skilfulness and carefulness of the staff regarding registration services (Table IV).

Table IV: Distribution of the respondent's satisfaction towards OPD services regarding quality of care $(\mathrm{N}=328)$

\begin{tabular}{|c|c|c|c|c|c|}
\hline \multirow[t]{2}{*}{ Parameter } & \multicolumn{5}{|c|}{ Level of satisfaction } \\
\hline & $\begin{array}{l}\text { Strongly } \\
\text { satisfied } \\
(\%)\end{array}$ & $\begin{array}{l}\text { Satisfied } \\
\qquad(\%)\end{array}$ & $\begin{array}{c}\text { Neither satisfied } \\
\text { nor dissatisfied } \\
(\%)\end{array}$ & $\begin{array}{l}\text { Dissatisfied } \\
\qquad(\%)\end{array}$ & $\begin{array}{c}\text { Strongly } \\
\text { dissatisfied } \\
(\%)\end{array}$ \\
\hline $\begin{array}{l}\text { Doctors were competent } \\
\text { and well trained }\end{array}$ & $62(18.9)$ & $254(77.4)$ & $11(3.4)$ & $1(0.3)$ & $00(0)$ \\
\hline $\begin{array}{l}\text { Doctors are good about } \\
\text { explaining the reason for } \\
\text { medical test }\end{array}$ & $41(12.5)$ & $209(63.7)$ & $63(19.2)$ & $15(4.6)$ & $00(0)$ \\
\hline $\begin{array}{l}\text { Nurse skill in using } \\
\text { medical equipment and } \\
\text { very cooperative }\end{array}$ & $45(13.7)$ & $213(64.9)$ & $55(16.8)$ & $14(4.3)$ & $1(0.3)$ \\
\hline $\begin{array}{l}\text { Pharmacist explain } \\
\text { clearly } \\
\text { and accurately on } \\
\text { drug prescription }\end{array}$ & $35(10.7)$ & $229(69.8)$ & $32(9.8)$ & $21(6.4)$ & $11(3.4)$ \\
\hline $\begin{array}{l}\text { Registration service } \\
\text { staff are trained } \\
\text { and systematic }\end{array}$ & $17(5.2)$ & $233(71.0)$ & $67(20.4)$ & $11(3.4)$ & $00(0)$ \\
\hline
\end{tabular}

Figure 1 shows that $52.7 \%$ patients were neither satisfied nor dissatisfied with health care services, $145(44.2 \%)$ patients were satisfied and only $10(3.0 \%)$ patients were dissatisfied with health services obtained from the primary health care centre. A statistically significant relation was found between educational level $(p=0.001)$, occupation $(p=0.001)$ and religion $(p=0.003)$ with satisfaction level of the respondents (Table V).

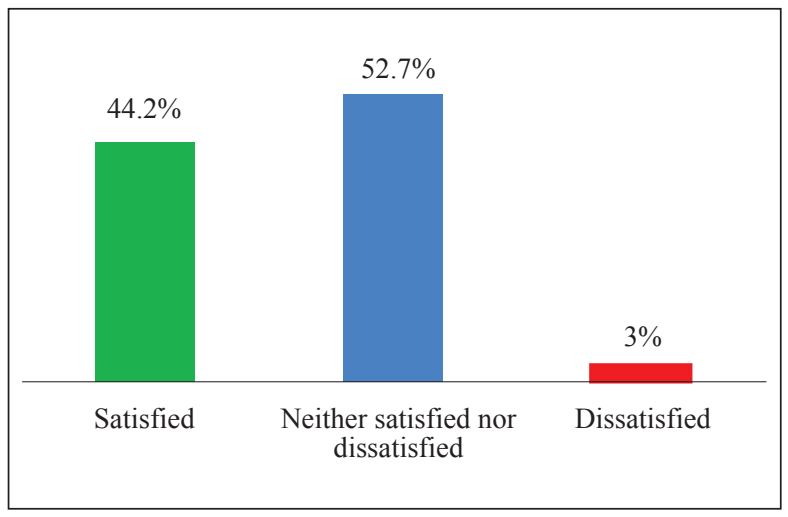

Fig. 1: Overall patient satisfaction
Figure 1 shows that $173(52.7 \%)$ patients were neither satisfied nor dissatisfied with health care services, $145(44.2 \%)$ patients were satisfied and only $10(3.0 \%)$ patients were dissatisfied with health services obtained from the primary health care centre.

Table V: Association of socio-demographic factors with satisfaction

\begin{tabular}{|c|c|c|c|c|}
\hline \multirow[b]{2}{*}{ Independent variable } & \multicolumn{4}{|c|}{ Satisfaction level } \\
\hline & $\begin{array}{l}\text { Satisfied } \\
(\mathrm{n}=145)\end{array}$ & $\begin{array}{l}\text { Uncertain } \\
(\mathrm{n}=173)\end{array}$ & $\begin{array}{l}\text { Dissatisfied } \\
\quad(\mathrm{n}=10)\end{array}$ & p-value \\
\hline \multicolumn{5}{|l|}{ Age (year) } \\
\hline$[\mathrm{Mean} \pm \mathrm{SD}]$ & $33.8 \pm 13.2$ & $33.0 \pm 13.9$ & $29.6 \pm 12.1$ & $0.584^{\#}$ \\
\hline \multicolumn{5}{|l|}{ Gender } \\
\hline - Male & $72(49.7)$ & $73(42.2)$ & $6(60.0)$ & $0.276^{\#}$ \\
\hline - Female & $73(50.3)$ & $100(57.8)$ & $4(40.0)$ & \\
\hline \multicolumn{5}{|l|}{ Occupation } \\
\hline - Housewife & $59(40.7)$ & $79(45.7)$ & $0(0.0)$ & \\
\hline - Agriculture worker & $24(16.6)$ & $16(9.2)$ & $1(10.0)$ & \\
\hline - Day laborer & $24(16.6)$ & $14(8.1)$ & $0(0.0)$ & $0.001^{\#}$ \\
\hline - Service holder & $16(11.0)$ & $22(12.7)$ & $4(40.0)$ & \\
\hline - Other & $22(15.2)$ & $42(24.3)$ & $5(50.0)$ & \\
\hline \multicolumn{5}{|l|}{ Education } \\
\hline $\begin{array}{l}\text { - Illiterate/no } \\
\text { schooling }\end{array}$ & $27(18.6)$ & $42(24.3)$ & $1(10.0)$ & \\
\hline - Primary & $60(41.4)$ & $58(33.5)$ & $0(.0)$ & \\
\hline - Secondary & $46(31.7)$ & $43(24.9)$ & $4(40.0)$ & $0.001^{\#}$ \\
\hline $\begin{array}{l}\text { - Higher secondary } \\
\text { and above }\end{array}$ & $12(8.3)$ & $30(17.3)$ & $5(50.0)$ & \\
\hline
\end{tabular}

Family income per

month (Tk.)

$[\mathrm{Mean} \pm \mathrm{SD}]$

$16098 \pm 9682 \quad 16861 \pm 10799 \quad 19055 \pm 11091 \quad 0.015^{\# \#}$

Figure in parentheses indicate percentage (\%) \#Chi-square test was done to measure the level of significance \#\#ANOVA was done to measure the level of significance

\section{Discussion}

The purpose of this study was to assess the satisfaction of patients with primary health care system in Bangladesh. The study showed that majority of the respondents were satisfied with the basic amenities such as seating arrangement, cleanliness, lighting arrangement and fans, etc. Overall, patients (44.2\%) who attended Upazilla health complex Dhamrai, Dhaka during the study period were neither satisfied nor dissatisfied with health care services. 
In the present study majority of the respondents were female (54\%) and $42.1 \%$ were house wives. A large number of female patients may be explained due to the fact that OPD hours are in the morning when most of the men are at work. This finding was consistent with the study done in Chandigarh. ${ }^{11}$ In present study $68.6 \%$ patients were satisfied with cleanliness of the hospital. A similar study done in Chandigarh showed that $89 \%$ patients were satisfied with cleanliness. ${ }^{11}$ Another study done in Islamabad, Pakistan observed that $90.5 \%$ patients were satisfied with cleanliness of hospital $^{12}$ and studydone in Madhya Pradesh India $^{13}$ also found $65 \%$ patients satisfied with cleanliness.

A study done in Puducherry noted that $85 \%$ patients were satisfied with the toilet facility ${ }^{14}$ and another study showed that satisfaction towards availability of toilets was $44 \%{ }^{13}$ which is less than our study finding (72\%). In our study, 44.8\% reported about unavailability of safe drinking water. This finding is not consistent with the finding of a study done in Puducherry. ${ }^{14}$

The present study observed that majority of the patients expressed satisfaction towards OPD services regarding courtesy and quality of care. The patients were more satisfied with the behaviour of doctors as compared to the behaviour of nurses, pharmacists and other staff. Studies conducted in Lucknow ${ }^{15}$ and Chandigarh ${ }^{11}$ noted that, the satisfaction towards doctor-patient relationship was found to be $60.5 \%$ and $65 \%$ respectively but our study showed that $96.6 \%$ patients were satisfied with the behaviour of doctors. The satisfaction towards behaviour of the health staff was found to be $82 \%$ and $78.3 \%$ respectively in lucknow ${ }^{15}$ and Madhya Pradesh ${ }^{13}$ in India which are similar to our study (83.5\%).

In the present study, overall level of patient's satisfaction regarding healthcare services was found $52.7 \%$ in average. This finding did not correlate with other studies where overall level of patient's satisfaction was satisfactory. ${ }^{16-20}$ Astudy conducted in Srinagar, India ${ }^{20}$ reported that
$6.7 \%$ patients were poorly satisfied with hospital services which was just twice to our study finding $(3 \%)$.

The present study showed a significant relation between educational level of the patient $(p=0.001)$ and satisfaction level of the respondents. Similar findings were observed in a study in Chandigarh and rural Bengal of India. ${ }^{11,21}$

This study reflects the satisfaction level of a small segment of a health centre of the country, Due to fund, logistics and other supports detail study with large sample size could not be conducted and it was confined to a limited numberof samples. It is recommended that further study to be conducted in both urban and rural health care centres to assess the situation for proper planning, implementation and monitoring, so that patient satisfaction level are further improved and ensured by a health care authority and other concerned organizations.

\section{References}

1. Andaleeb SS. Service Quality Perceptions and Patient Satisfaction: A Study of Hospitals in Developing Countries. Soc Sci Med. 2001; 52(9):1359-70.

2. Verma A, Sarma RK. Evaluation of the Exit Proformas in Use at Special Wards of Public Sector Tertiary Care Center. Journal of Academy of Hospital Administration. 2000;12(1):1-6.

3. Sreenivas T, Prasad G. Patient Satisfaction - A Comparative Study. Journal of Academy of Hospital Administration. 2003;15(2):7-12.

4. Kumar R. Medical Documentation - Patient Satisfaction Document. Journal of Academy of Hospital Administration. 2003;15(1):1-6.

5. Bhattacharya A, Menon P, Koushal V, Rao KLN. Study of Patient Satisfaction in a Tertiary Referral Hospital. Journal of Academy of Hospital Administration. 2003;15(1):1-6

6. Brijender S, Sarma RK, Sharma DK, Vijender S, Sanjay A, Deepak. Assessment of Hospital Services by Consumers: A Study from NDDTC, AIIMS, Ghaziabad. Medico Legal Update. 2005;5(1):1-3. 
7. Kulkarni MV, Dasgupta S, Deoke AR, Nayse. Study of Satisfaction of Patients Admitted in a Tertiary Care Hospital in Nagpur. National Journal of Community Medicine. 2011;2(1):37-39.

8. Lochoro P. Measuring Patient Satisfaction in UCMB Health Institution. Health Policy and Development. 2004;2(3):243-48.

9. Margolis SA, Al-Marzouq S, Revel T, Reed RL. Patient Satisfaction with Primary Health Care Services in the United Arab Emirates. Journal in Health Care. 2003;15(3):241-49.

10. Mc Leod SA. Likert Scale. Simply Psychology [Internet]. 2008 [cited 2016 June 15]. Available from: http://www.simplypsychology.org/likertscale.html.

11. Galhotra A, Sarpal SS, Gupta S, Goel NK. A Cross-Sectional Study on Patient Satisfaction Toward Services Received at Rural Health Centre, Chandigarh, North India. Ann Trop Med Public Health. 2013;6(2):240-44.

12. Javed A. Patient Satisfaction towards Outpatient Department Services in Pakistan Institute of Medical Sciences, Islamabad [thesis]. Bangkok: Mahidol University; 2005.

13. Sodani PR, Kumar R, Srivastava J, Sharma L. Measuring Patient Satisfaction: A Case Study to Improve Quality of Care at Public Health Facilities. Indian J Community Med. 2010;35(1):52-56.

14. Raghunath E, Vijayalakshmi S, Sathagurunath PA. A Study of Outpatient Satisfaction at Primary Health Centers in Puducherry. The Health Agenda. 2013;1(4):118-21.
15. Kumari R, Idris MZ, Vidya B, Khanna A, Agarwal M, Singh SK. Study on Patient Satisfaction in the Government Allopathic Health Facilities of Lucknow District, India. Indian J Community Med. 2009;34(1):35-42.

16. Singh JP, Kariwal P, Singh DK. An Assessment of Patients Satisfaction with Services Obtained from a Primary Urban Health Centre, Bareilly (UP). Sch J App Med Sci. 2014;2(5D):1746-50.

17. Sohrabi MR, Albalushi RM. Clients' Satisfaction with Primary Health Care in Tehran: A Cross-Sectional Study on Iranian Health Centers. J Res Med Sci. 2011;16(6):756-62.

18. Hizlinda T, Teoh SY, Siti Nurbaiyah KE, Azrina AS, Hafizuddin MMT, Chang LH, et al. A Cross-Sectional Study on Patient Satisfaction with Universiti Kebangsaan Malaysia Medical Centre (UKMMC) Primary Care Clinic. Med and Health. 2012;7(1):12-23.

19. Mohamed EY, Sami W, Alotaibi A, Alfarag A, Almutairi A, AlanziF. Patients' Satisfaction with Primary Health Care Centers' Services, Majmaah, Kingdom of Saudi Arabia. Int J Health Sci (Qassim). 2015;9(2):163-70.

20. Qureshi W, Khan N, Naik A. A Case Study on Patient Satisfaction in SMHS Hospital, Srinagar. JK Practitioner. 2005;12(3):154-55.

21. Das P, Basu M, Tikadan T, Biswas GC, Mridha P, Pal R. Client Satisfaction on Maternal and Child Health Services in Rural Bengal. Indian J Community Med. 2010;35:478-81. 